Financial Statistical Journal (2018) Volume 1 doi: $10.24294 /$ fsj.v1i2.913

\title{
Addressing climate change adaptation with a stochastic integrated assessment model: Analysis of common agricultural policy measures
}

Tatiana Ermolieva ${ }^{1 *}$, Esther Boere ${ }^{1}$, Anne Biewald ${ }^{2}$, Petr Havlík ${ }^{1}$, Aline Mosnier ${ }^{1}$, David Leclere ${ }^{1}$, Hugo Valin ${ }^{1}$, Stefan Frank ${ }^{1}$, Michael Obersteiner ${ }^{1}$, Yuri Ermoliev ${ }^{1}$

${ }^{1}$ International Institute for Applied Systems Analysis, Austria

${ }^{2}$ Federal Environment Agency, Germany

\section{ABSTRACT}

Stochastic agro-economic model GLOBIOM is used to demonstrate how best to design and evaluate the CAP's financial and structural measures, both individually and jointly, in the face of inherent uncertainty and risk. The model accounts for plausible shocks simultaneously and derives measures that are robust against all shock scenarios; it can thus help avoid the irreversibility and sunk costs that occur in unexpected scenarios.To allow adequate agricultural production, we show that the distribution of CAP funds needs to account for exposure to risks, security targets, and the synergies between policy measures, including production, trade, storage, and irrigation technologies. ${ }^{1}$

Keywords: Climate Change; Stochastic Integrated Assessment Model; Common Agricultural Policy; Adaptation; Robust Policies; GLOBIOM

\section{Introduction}

Climate change and variability are expected to have significant (Heal and Kriström 2002) and highly uncertain impacts on agricultural production and the utilization of natural resources, affecting food, water, environmental, and (bio)energy (FWEE) security at national and regional levels, with the potential for world-wide spillovers (OECD2009; Ray et al. 2015). Different regions will be subject to different types of exposure. To ensure adequate agricultural production and thus food security at the level of EU countries and main economic regions, an analysis of local agricultural adaptation strategies has to be designed and implemented to tackle uncertainties: such strategies include decisions on governmental regulations, investment in and reform of water management, land use practices, agrofood production patterns, and food trade regulations (European Commission 2009a).

It has been emphasized that climate adaptation is a major concern of the Common Agricultural Policy (CAP) of the European Union (EU). In the proposed CAP regulations for 2014-2020, adaptation has gained great prominence, with "the sustainable use of natural resources and climate action" being one of the core objectives. Proper appraisal of CAP policies can increase the productive capacity and viability of the agricultural land-based sectors of the EU faced with climate change and variability (European Commission 2013).

In this paper, we study synergies and trade-offs among different measures of the new Common Agricultural Policy (CAP); our aim is to identify the principles that can ensure the most effective distribution of CAP funds to achieve optimal climate change adaptation in the face of inherent uncertainty and risk.

The CAP is organized into two pillars. The measures supported under the first pillar are financial, and can be defined as short-term. While these can be instantly reversed or adjusted to react to sudden production or market shocks, the effects they have can be long-lasting and even irreversible. The measures under the second pillar are concerned with more strategic long-term restructuring of local production capacities, natural resource utilization, and investments in new technologies that are important for reaching sustainable rural development and climate change adaptation goals in the longer term. Examples are grain storage, irrigation capacities, and water reservoirs.

Copyright (C) 2018 Tatiana Ermolieva et al.

doi: $10.24294 /$ fsj.v1i2.913

EnPress Publisher LLC.This work is licensed under the Creative Commons Attribution-NonCommercial 4.0 International License (CC BY-NC 4.0). http://creativecommons.org/licenses/ by/4.0/

\footnotetext{
${ }^{1}$ Research is funded by ECONADAPT (603906), AGRICISTRADE (612755), COACCH (776479) EU FP7 projects.
} 
The ongoing CAP reform aims to flatten the basic payments of pillar I, so that farmers receive the same level of support for every hectare of eligible agricultural land across EU countries, independently of: i) the type of farm; ii) what crop is grown (European Commission2013); iii) the risks from climate change and variability; and iv) agricultural production vulnerability and potentials in the face of changing climate and increasing climate variability.

This paper argues that risks and vulnerability are highly significant in the interdependencies between pillar I and pillar II measures, and must therefore be properly accounted for in analyses of the new CAP, in particular, the optimal allocation of CAP funds between and within the pillars at different levels. Traditionally, analysis and appraisal of policies by European Commission are based on a measure-by-measure "what-if" analysis using deterministic models and methodologies (e.g.,CAPRI model in European Commission (2011); IFM-CAP model, JRC (2015); European Parlament, 2010; Gohin 2006; Balkhausen et al. 2007; Rosegrant 2012;Nelson et al. 2013) both for regional and farm-level analysis; scenario-dependent recommendations are derived.

To derive robust conclusions, we use the stochastic agro-economic model GLOBIOM (Havlík et al. 2011; Ermolieva et al. 2016a). Stochastic GLOBIOM simultaneously employs different historical (1960-2016) yield shock scenarios in order to derive a combination of risk-hedging measures that are optimal and robust with respect to all scenarios (Ermoliev and Hordijk, 2003). We show that in the presence of uncertainties, pillar I subsidies calculated using stochastic GLOBIOM ("robust") and accounting for risk exposure, profitability, and adaptive capacity of member states, ensure more robust agricultural production at the level of EU countries and main economic regions than the "flat" subsidies.

Our model results demonstrate numerically that a proper interdependent analysis and appraisal of the EU CAP measures under uncertainty and risks will ensure mainstreaming of climate change uncertainty, risk management approaches, and robust actions within the CAP implementation plans (European Commission 2009b). The recommendations of the stochastic model have been summarized in a deliverable to the EU Commission (ECONADAPT 2016; Ermolieva and Biewald et al. 2016b).

The paper is organized as follows. Section 2 provides an overview of the new 2014-2021 CAP. Section 3 presents a stylized fragment of stochastic GLOBIOM, demonstrating how a proper mix of short-term operational and long-term strategic decisions, together with the synergies they create, can play a role in hedging inherent risks. In Section 3, we also show that the optimal mix depends on complex non-smooth interactions among the systems, feasible adaptation measures, and probability distributions of uncertain parameters (e.g., yield shocks). In particular, we discuss that changing the structure of pillar I direct payments to a "flat" rate across the EU countries (European Commission 2011) can have negative consequences (Helming and Peerlings 2014; Koundouri et al. 2009). We also identify the sources of systemic risks emerging due to potential imbalances (as, for example, in demand-supply) that are catalyzed by random yield shocks. Section 4 outlines the scenarios of CAP measures studied individually and jointly, as well as selected results from the studies. A summary of conclusions is found in section 5 .

\section{CAP reform}

Before using stochastic GLOBIOM to investigate interdependencies and robust mix of CAP measures, we provide a summary of the new 2014-2020CAP, an extended form of which is available in European Commission reports of 2009, 2013, 2011, 2014, 2015, and 2017.

\subsection{New CAP: Challenges and goals.}

The CAP seeks to protect viable food production, ensure sustainable management of natural resources, and support rural vitality by pooling European Union resources. The total 2014-2020 CAP accounts for about $40 \%$ of the total EU budget. The CAP has two pillars. The first pillar includes direct payment sand market measures. Under pillar I about $€ 58$ billion in subsidies is distributed to farmers, generating about $2 \%$ of EU GDP. French farmers receive the most subsidies with about $17 \%$ of CAP payments, followed by Spain (13\%), Germany (12\%), Italy (10.6\%), and the UK (7\%). Larger producers receive more from the CAP than small farmers; about $80 \%$ of aid goes to about $25 \%$ of EU farmers. Pillar II is funded through the European Agricultural Fund for Rural Development (EAFRD), which was worth about $€ 100$ billion from 2014-2020. Each EU country receives a financial allocation for the 7-year period (European 
Commission, Rural development, 2014-2020). Member states and regions elaborate their rural development programs based on their own needs and on EU priorities, for example, enhancing the viability and competitiveness of all types of agriculture; promoting innovative farm technologies and sustainable forest management; fostering knowledge and innovation in agriculture, forestry, and rural areas; promoting food chain organization, animal welfare, and risk management in agriculture; restoring, preserving, and enhancing ecosystems related to agriculture and forestry; promoting resource efficiency and supporting the shift toward a low-carbon and climate-resilient economy in the agriculture, food, and forestry sectors; and promoting social inclusion, poverty reduction, and economic development in rural areas.

One of the challenges identified in the 2014-2020 CAP is to maintain food security, which has once again become an issue with food prices rising in recent years. A major focus of the new CAP is on the adoption of actions aimed at climate change management and the promotion of the sustainable management of natural resources.

\subsection{Direct subsidies (pillar I).}

Direct annual payments to farmers are provided to help stabilize farm revenues under bad weather conditions and potentially volatile markets. The payments, which aim to incentivize farmers to demonstrate good environmental behavior, can be considered as a reward to farmers for providing environmentally friendly "services" such as preservation of good practices, increasing farmland biodiversity, and hedging against climate change risks. They also aim to support farmers' incomes and enhance food security. Under the 2003 reforms, direct payments were decoupled from production but linked to eligible farmland. Countries could choose what defined eligible farmland based on i) farm-specific "historic" reference amounts; ii) regional reference margins; or iii) a hybrid of the historic regional references (European Commission, 2014). While the European Commission expressed a preference for ii), the majority of countries opted for i) (Matthews et al. 2013). Under the "historic" approach, only land growing specific crops was considered eligible for fixed payments $(€ /$ ha) and these varied according to crop, based on historic 2000-2002 yields.

The CAP reform of 2013 introduced a basic payment scheme that would provide the same "flat" level of support to every hectare of agricultural land within a region, irrespective i) of the type of farm or crop grown (European Commission, 2013); and ii) of the regional production potentials or risks.

While the flattening of subsidies can introduce more fairness into agriculture, it can also distort the attainability of other important CAP objectives, for example: i) promoting technical progress to increase agricultural productivity while trying to ensure optimum use of the factors of production, in particular, labor; ii) stabilizing markets-a crucial challenge, given the frequent alternation between sharp increases in global food prices and severe price depression; iii) ensuring supply availability; and iv) ensuring reasonable prices for consumers.

We argue that, to achieve sustainable agricultural production in the EU, payments have to account for i) the local and global risks that characterize farmers' exposure; ii) the vulnerability and/or profitability; and iii) technological potential of locations.

In section 3 we explain how robust payments (Figure 1) can be calculated with stochastic GLOBIOM, and in section 4 we compare the effects of the "robust" payments with the other two types of payment; in other words, we compare the effects of the following payments: i) payments based on farm-specific historical reference amounts that were in place before the 2013 CAP reform (Commission, 2011); ii) the flat-rate payments, introduced in the 2013 CAP reform; and iii) a robust approach, based on calculations with stochastic GLOBIOM, taking into account risk exposure, profitability, and adaptive capacity of member states.

\subsection{Rural development (pillar II).}

Pillar II finances long-term projects, for example, investments in advanced irrigation and water-saving technologies, and grain and water storage infrastructure. The economic measures of pillar II aim to contribute to the sustainable development of a region by improving the stability of economic returns. For example, grain storage allows harvested products to be preserved and delivered when most needed, such as transferring grains from good to bad years 
to ensure food-feed-biofuel-water security. As storage hedges production risks, it also reduces the demand for other climate change adaptation and risk hedging measures, both financial and structural, for instance, by reducing the commitment of arable land to production and thus the impact of agriculture on the environment.

Advances in water technologies are also an important part of pillar II measures. Agriculture is a major consumer of water, placing a large burden on available water resources and threatening water security. While proper irrigation can be beneficial to regional sustainability and provide greater yield stability under variable weather conditions, it can also lead to negative impacts, especially in water-scarce areas with multiple water-dependent systems (IEEP 2000), where the over consumption of water by one sector (e.g., agriculture) can lead to water shortages and systemic failures in another (Ermolieva et al., 2016).

\subsection{Synergies between land use systems and adaptation measures.}

Because of the existing interdependencies, the ways in which CAP policies will evolve in one region will likely have implications for other regions and globally. The implementation of CAP measures could alter regional land uses and trigger changes in other regions. For example, direct payments or other available forms of income support (for instance, state or private insurance, subsidies, etc.) will guarantee some income and compensate for some potential production losses. Farmers can thus be less concerned about production risks, and this could discourage them from maintaining a certain production level or investing in longer-term risk-hedging structural measures, such as grain or water storage, to reduce vulnerability to climate risks.

It can be argued that ensuring the security of production by means of a structural measure can reduce or eliminate the need for other measures. On the other hand, if climate change and production risks associated with, for example, weather vulnerability are not as severe as expected, investments used to implement the adaptation may be lost. Pillar II measures may thus divert capital (funds) from other projects and lead to sunk costs should climate change or weather variability not be as severe as expected. If the combination of financial and structural measures is inadequate, there could be decreasing production, tightening agricultural markets, increasing prices, a stimulus to land expansion, increasing environmental pollution, and misuse of water for irrigation.

\section{Analysis of CAP measures using stochastic GLOBIOM}

How can an optimal and robust portfolio of interdependent measures be evaluated in the face of uncertainties and risks? In this section, similar to (Ermolieva et al., 2016), we use a stylized version of stochastic GLOBIOM model in order to illustrate how different types of decisions, uncertainties and risks interact with and can affect one another. We emphasise, contrary to the results of CAPRI model (European Commission, 2011), that considerations of risks and slight alteration of costs, e.g. by changing subsidies structure, can affect production allocation by regions (farmers). We also show that explicit accounting for risks will alter the composition of production units and their intensification levels towards more robust and risk-adjusted levels.

\subsection{Modeling interdependencies between CAP measures: Strategic and operational decisions}

Stochastic GLOBIOM is a complex multi-region model incorporating various agricultural goods and production and processing systems. To show the interdependencies between risks and different measures as they are introduced in stochastic GLOBIOM, this section uses its stylized version with only two regions (or producers), $i=1,2$, producing the same good (grain or livestock commodities). Let $x_{1}$ denote the production level of $i$-th region. In general, the variable can also stand for the amount of land allocated for production. The costs of region $i$ per unit of produce (or hectare) are denoted by $c_{i}$ and $c_{l}<c_{2}<b$, i.e., the second region has higher costs. The goal of the production is to satisfy the exogenous inelastic demand $d$. Because of climate change and weather variability, production can be distorted by shocks $a_{1}(\omega)$ and $a_{2}(\omega), 0 \leq a_{i}(\omega) \leq 1, i=1,2$, where $\omega$ represents stochastic events such as droughts, heavy precipitation, and increasing instances of cropand livestock diseases. Random events $\omega$ can be characterized by a finite number of scenarios (Kall and Mayer 2004), affecting the regions simultaneously or independently. These shocks can reduce production $x_{1}$ and $x_{2}$ differently indifferent regions.

The goal of robust production planning is to minimize the total costs: 


$$
c_{1} x_{1}+c_{2} x_{2}
$$

under the food security constraint

$$
a_{1}(\omega) x_{1}+a_{2}(\omega) x_{2} \geq d
$$

The main question is how (in the face of uncertainty) to allocate production $x_{1}$ and $x_{2}$ exante before knowing exact information about shocks so that the constraint (2) is fulfilled under all (or almost all) possible shock scenarios $\omega=\left(\omega_{1}, \omega_{2}, \ldots \omega_{s}\right)$. If supply $a_{1}(\omega) x_{1}+a_{2}(\omega) x_{2}$ falls short of demand $d$ after actual yields become known, the residual amount $y(x, \omega)=d-a_{1}(\omega) x_{1}-a_{2}(\omega) x_{2}$ can come expost either from the market, or from a storage facility, or compensated by insurance or subsidiesat per unit price $b$. The shortfall $y(x, \omega)$ in a sense determines the demand for new, possibly not yet existing, measures, both structural and financial, to cover the shortfall. The concept of two types of decisions (two-stage) modeling with interdependent strategic exante (taken in front of uncertainties) $x_{1}, x_{2}$ and operational expost (after uncertainty scenario becomes known) decisions $y(x, \omega)$ is critically important for robust planning in the face of uncertainties and risks, as these decisions ensure the security constraint (2) for any event $\omega$ (Ermoliev and von Winterfeldt, 2012).

The model (1)-(2) is formulated as a linear two-stage stochastic optimization (STO) model: minimize the costs function

$$
c_{1} x_{1}+c_{2} x_{2}+b E y(x, \omega) .
$$

The scenario-dependent shortfalls $y(x, \omega)=\max \left\{0, d-a_{1}(\omega) x_{1}-a_{2}(\omega) x_{2}\right\}$ characterize interdependencies and trade-offs among strategic decisions $x$ and operational decisions $y(x, \omega)$, shocks $a_{1}(\omega)$ and $a_{2}(\omega)$, costs $c$, price $b$, demand $d$, and the risks of not fulfilling constraint (2). Changing parameters $c_{1}$ and $c_{2}$ on local (country or regional) and $b$ and $d$ on the global (national and international) levels due to various interventions, for example, subsidies or taxes,can - if risks are not accounted for-cause production to be redistributed toward a more risk-exposed region and lead to the increase of the shortfall and to systemic failure.

\subsection{Robust production allocation}

The goal of subsection is to show how production level that is robust and resilient to shocks is determined by risk exposure and (net) costs. Redistribution of CAP subsidies can stimulate allocation of production to a riskier region. Assume that only region 1 is exposed to risk. The optimal positive production $x_{1}^{*}>0, x_{2}^{*}>0$, occurs when the derivatives $F x_{1}(0,0)$ and $F x_{2}(0,0)$ of the goal function $F(x)$ are such that $F x_{1}(0,0)=c_{1}-b E a_{1}(\omega)<0$ and $F x_{2}(0,0)=c_{2}-b<0$ (see Ermolieva et al. 2016). As condition $c_{2}-b<0$ is fulfilled independently of random shocks $\omega$, the risk-free, less efficient region 2 must always be active. The cost-efficient, risk-exposed region 1 is inactive in the case $c_{1}-b E a_{1}(\omega) \geq 0$. In this situation, the higher-cost, risk-freeregion 2 acts as "insurance" for fulfilling food security. Both regions are active only if $c_{1}-b E a_{1}(\omega)<0$. Thus, the optimal robust production of a region depends on its risk exposure and (net) costs.

From the optimality condition $F_{x_{n}}\left(x_{1}, x_{2}\right)=c_{2}-b P\left(d>a_{1}(\omega) x_{1}+x_{2}\right)=0$ of stochastic minimax problems (see, e.g., Dantzig and Madansky 1961, Ermoliev and Wets 1988, and references therein) we can derive optimal production level $x_{1}^{*}$ and $x_{2}^{*}$ from

$$
P\left(d>a_{1}(\omega) x_{1}^{*}+x_{2}^{*}\right)=c_{2} / b
$$

This means that the probability of shortfall under robust decisions is equal to the ratio of $c_{2} / b$ defined by the cost $c_{2}$ and import price $b$. The optimal production level $x_{2}^{*}>0$ of risk-free region 2 is a quantile of the probability distribution defined by the shocks $a_{1}(\omega)$ of risk-exposed region 1 , decisions $x_{1}^{*}$ of region 1 , the costs of region 2 , and the import price $b$.

\subsection{General stochastic GLOBIOM and robust subsidies}

Previous subsections explain with a stylized version of stochastic GLOBIOM the interdependencies between the optimal and robust long-term strategic $x^{*}$ (e.g. land allocation by regions, crops, management systems; (grain, water, (bio)energy) storage capacity) and the short-term operational scenario-dependent decisions $y^{*}(x, \omega)$ (trade, storage 
control, insurance, subsidies). The general stochastic GLOBIOM includes many more interdependencies between variables and parameters, including costs, prices, demand-production-trade interactions between locations and land use sectors, security constraints, location and crop-specific yield shocks for 28 world regions. The goal function of stochastic GLOBIOM includes the expected producer and consumer surpluses and various costs of all world countries subject to biofuel targets, GHG emissions, and resource constraints (Ermolieva et al., 2016). Depending on the land use activities, security constraints are introduced as follows. The food security constraint ensures that the energy intake from food production cannot be lower than the minimum number of kilocalories needed to satisfy dietary requirements in cereals, vegetables, and animal (meat and dairy) products, measured in kilocalories per capita (WHO 1985). Feed sources for livestock comprise crops, grass, and biofuel co-products (feed cakes). The feed security constraint ensures that feeds for livestock cannot be lower than the minimum livestock dietary requirements in energy measured in mega-calories. First-generation biofuels from crops and second-generation biofuels from lignocellulosic biomass (woody crops) and agricultural residues have to fulfill biofuel production targets. Food security constraints and biofuel security targets introduce competition for limited natural resources (land and water) among different land uses. Second-generation biofuels from forest production include biomass for woody energy and traditional fuelwood. The energy biomass can be converted through i) combined heat and power production; ii) fermentation for ethanol, heat, power, and gas production; and iii) gasification for methanol and heat production. Because of biofuel targets, agriculture and forestry have a joint biofuel security constraint similar to (2), which induces systemic risks across sectors and activities (Ermoliev and Winterfeldt, 2012). Through joint security constraints, a risk-free region or activity becomes risk-exposed. Production shortages are estimated at regional and global levels requiring additional decisions such as (grain, water, energy) storages, investments, insurance, financial instruments and other options, that must be constructed in proper locations (regions, countries, grids) to guarantee a desirable regional and global systemic security level.

Robust subsidies are calculated and applied in stochastic GLOBIOM (Figure 1) in two steps. First, the model runs without subsidies. At this step, profits from robust decisions $\left(x^{*}, y^{*}\left(x^{*}, \omega\right)\right)$ are calculated at country level under numerous constraints and performance indicators (Ermolieva et al., 2016). The profits from robust decisions are used to share down total Pillar I subsidies between the EU countries. Robust subsidies, therefore, are based on robust profits that are calculated taking into account FWEE security constraints, systemic interdependencies between the two types of decisions, demand-supply-trade balances, risk exposure, and other parameters defining the structure of the whole model.

There are several ways in which subsidies can be included and investigated using the model. In stochastic GLOBIOM, we use the so-called "income-based approach" according to which subsidies are included as income and not as capital, as in the "balance-sheet" approach. Thus, at the second step the model runs including subsidies, which reduce the net costs.

\section{Selected results}

Stochastic GLOBIOM accounts for spatial dependencies between yield shocks (FAO, 2016) and suggests policies, which are robust with respect to all shocks rather than with respect to only one scenario. Robust scenario-independent long-term strategic policies regarding production allocation and management technologies (e.g. irrigation, storage capacities, etc.) account for risk exposure, profitability and adaptive capacity of locations. The strategic policies are supplemented by scenario-specific geographically-diversified trade across uncorrelated (or negatively correlated) regions and commodities, by storage control (withdrawals) decisions, and by financial support measures such as insurance or subsidies. These instant operational decisions can be easily adjusted on an annual basis. In this section we discuss pillar 1 and pillar II CAP measures that have been analyzed with stochastic GLOBIOM.

\subsection{Robust payments of pillar I}

First, let us compare the effects of "robust"payments with the effects from the two alternative payments schemes, the "historic" and "flat" (Commission 2011): 
1. "Historic" direct payments reflect countries' past production and profitability. European Commission (2011) considered the decoupling of direct payments linked to historical support values as the most neutral design of support in terms of impact on farms' asset values.The "historic" payments reflect the conditions for agricultural production in a specific region, in particular, the differences in economic and natural conditions across the countries of EU.

2. The "flat" (or "EU average") payments scheme is based on providing the same level of aid per hectare to all farmers in the EU. The implementation of this scheme can lead to losses in countries where "historic" payments are above and to gains where "historic" payments are below the average.

3. "Robust" direct payments are calculated with stochastic GLOBIOM. The "robust" payments distinguish the EU member states by such factors as profitability, risk exposure and adaptive capacity, availability of risk-hedging options, self-sufficiency policies and environmental commitments of the EU countries. The "robust" payments can also include other agricultural, economic, and fairness criteria.

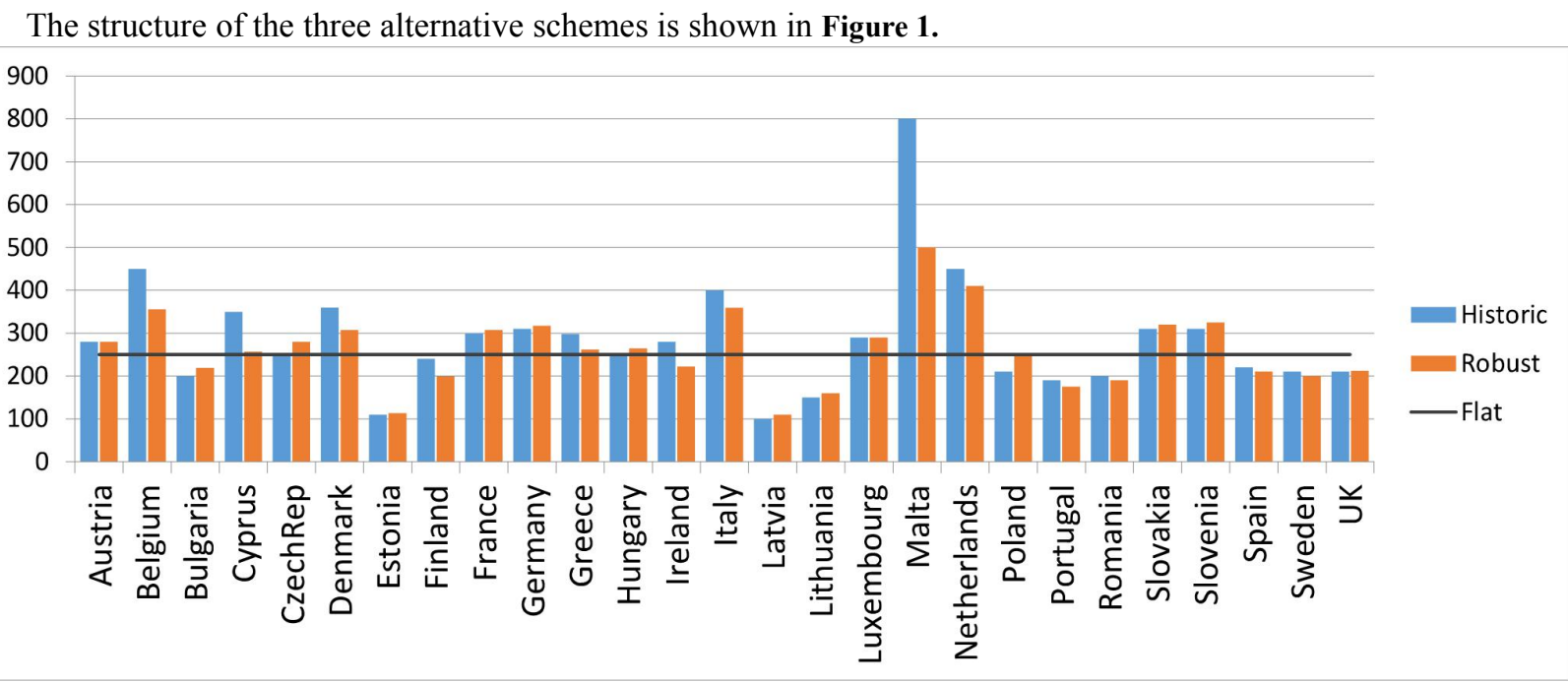

Figure 1; Alternative schemes for distribution of CAP pillar I payments across EU countries, in EUR/ha: "Historic", "Robust"; and "Flat".

In the model, we calculate the average level of direct payments at the EU28 level to be around $250 \mathrm{EUR} / \mathrm{ha}^{2}$. The three schemes are implemented in stochastic GLOBIOM per hectare of cultivated land and are compared in terms of demand and supply of major crops, land use change, irrigated land, and water consumption.

\subsubsection{Demand and supply of crops}

If aggregated from the country to the EU level, the effects of different payment schemes cancel each other out and are therefore not very pronounced. Nevertheless, at EU level the demand and supply of wheat, corn, rice, and soya under the "robust" scheme is calculated to be higher than under the "flat" scheme.Toward 2050 the supply of wheat is expected to beat least $20 \%$ higher under the "robust" than under the "flat"scheme.If the "robust"scheme is compared with the "historic" scheme, wheat production increase is slightly lower, namely, about $5 \%$. Corn production under the "robust" scheme could be about 9 and 3.5\% higher toward 2050, compared with the "flat" and "historic" schemes, respectively. Rice production increases by about $4 \%$ under "robust" than under "flat" scheme, and output of soya is expected to be higher by about 10 and $6 \%$ compared with the "flat" and "historic" schemes, respectively.

At the level of EU countries and economic regions, the effects of different payment schemes are more visible. Some countries and regions show substantial increases, while others show a decrease in supply and demand for the investigated crops under the "robust" scheme as compared to the "flat" and "historic" schemes.

\footnotetext{
2 Other approaches to “exogenous" allocation of payments can be tested ( MAX” or "MIN" rate); however, these schemes also do not account for risk considerations (European Commission 2011).
} 


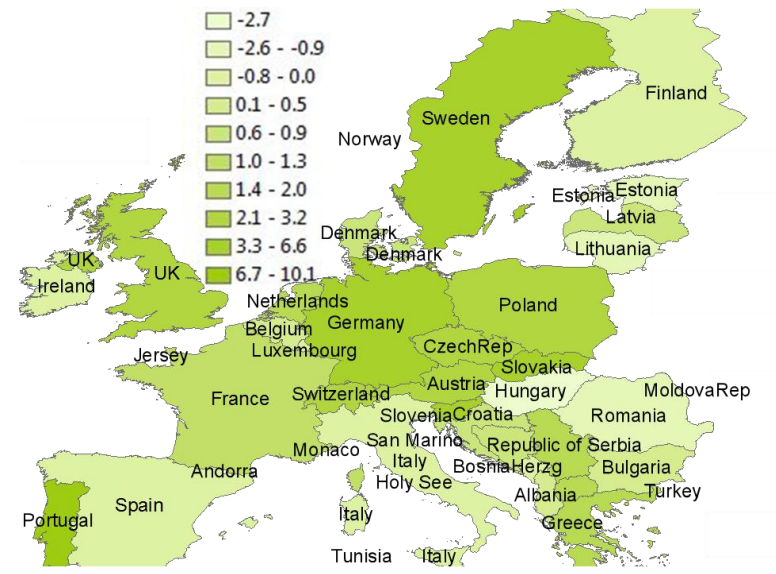

Figure 2a; Grain yields, in percentage change, from "historic" to "robust" subsidies.

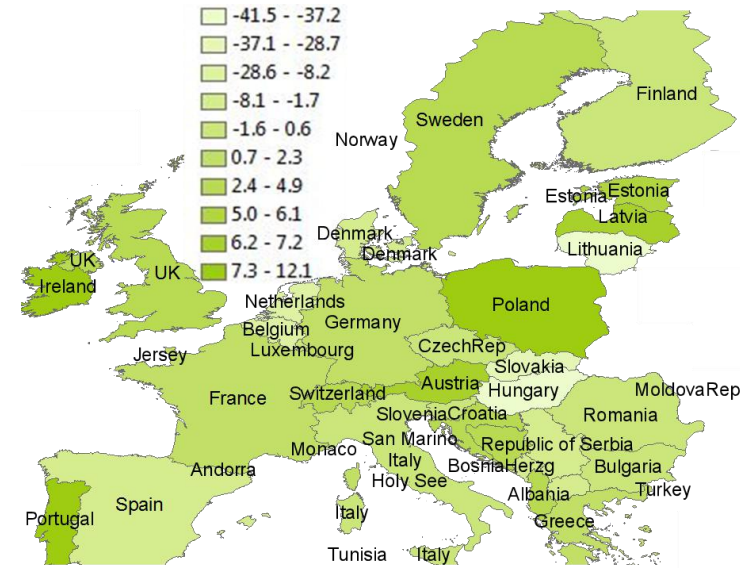

Figure 3a; Grain area, in percentage change,

from "historic" to "robust" subsidies.

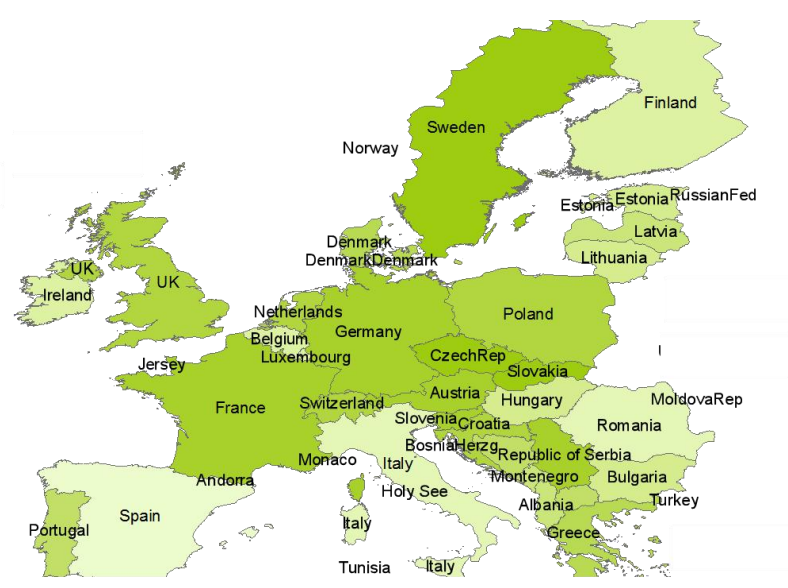

Figure 2b; Grain yields, in percentage change, from "flat" to "robust" subsidies.

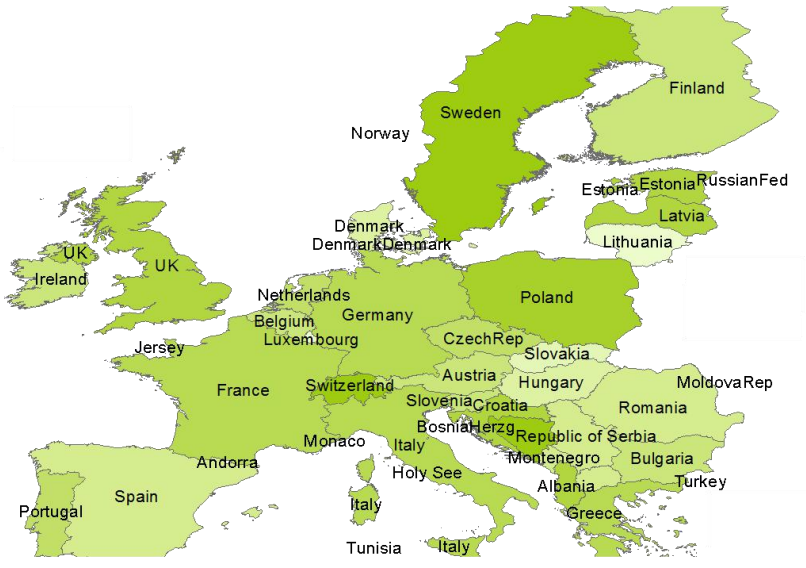

Figure 3b; Grain area, in percentage change, from "flat" to "robust" subsidies.

Figure 2a compares yield change and Figure 3a -grains production area change, under "historic" compared to "robust" subsidiese, in percentage change terms; and figures $2 \mathrm{~b}$ and $3 \mathrm{~b}$ compare yield and grains production area change under "flat" compared to "robust" subsidies. Darker green color indicates that in "robust" grain yield and production area are higher and lighter green, correspondingly, shows countries with yields and production areas under "robust" subsidies. For example, the implementation of robust payments will increase yields of farmers in central eastern countries (e.g., Slovakia, Slovenia, Bulgaria, Hungary, Poland) and middle western countries (e.g., Austria, Germany, France, Netherlands), where production of grains (e.g. wheat, corn, rice, soya) could increase by about $30 \%$. In the south (e.g., Spain, Portugal, Italy, Cyprus), the effects can be negative, production of main cereals could decrease by about14\%. Somewhat negative effects can be also expected in the Baltic and norther countries such as Estonia, Latvia, Lithuania, Finland as well as in Midwestern countries - Belgium, Luxembourg and in central east - Romania.

\subsubsection{Irrigated area expansion and water demand}

In the planning time horizon from 2010 to 2050, the "robust" payments reduce irrigated area and water consumption by about 4 and 11\%, respectively, compared to the "flat" scheme. The reduction in water demand is because "robust" paiments stimulate more efficient water management in more profitable and less risk-exposed regions with lower costs of advanced irrigation technologies. At the level of EU countries and regions, the effects are rather heterogeneous. For example, in Baltic and northern countries (e.g.,Latvia, Estonia, Norway, Sweden, Denmark) "robust" subsidies stimulate the expansion of irrigated area more than the "flat" scheme (Figure 4b) but less than the "historic" scheme (Figure 4a). In centraleast countries such as e.g., Hungary and Slovakia, the general trend under "robust" subsidies (if compared with "historic") is toward decreasing and if compared with "flat" - towards increasing the irrigated area. These differences across the scenarios can be intuitively explained by the interdependencies between 
the (net) costs, which are altered by subsidies (in some countries, "historic" subsidies are lower than "robust"), and by the yield shocks, which induce production risks in more exposed and vulnerable countries. With more details, the interdependencies are explained in section 3. In middlewest (e.g. Germany, France, Austria) and in north (Sweden), "robust" subsidies can stimulate the increase of irrigated area, but decrease water consumption, which indicates that these countries are able to introduce more efficient water saving irrigation technologies. In the southern region (e.g. Spain, Italy), "flat" subsidies lead to greater expansion of irrigated area than"historic" and "robust"subsidies, which can be explained by the shortage of water and inefficiency of investments into advanced irrigation (i.e., high water price).

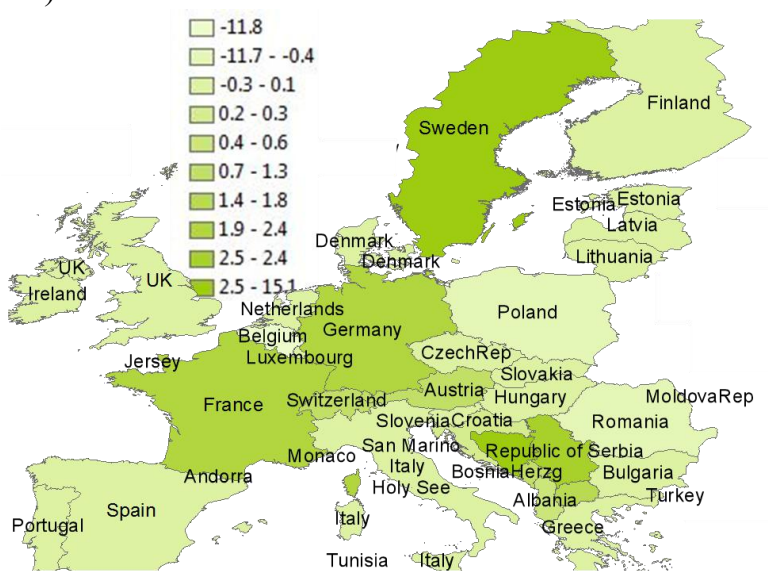

Figure 4a; Irrigated area, percentage change, from "robust" to "historic" subsidies.

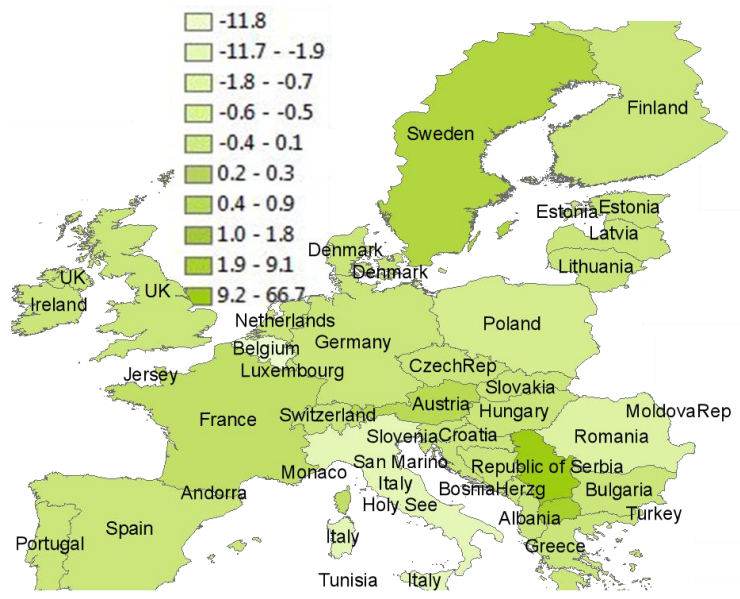

Figure 5a; Water demand, percentage change,

from "historic" to "robust" subsidies.

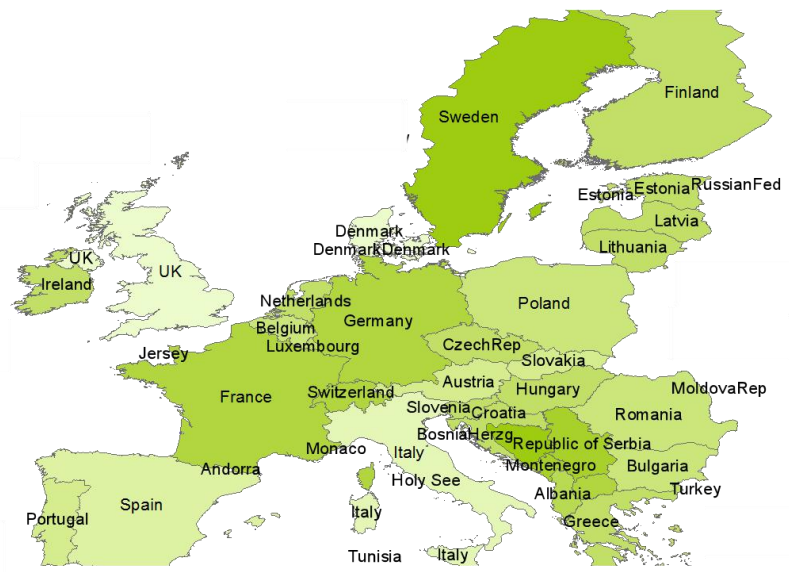

Figure 4b; Irrigated area, percentage change, from "robust" to "flat" subsidies.

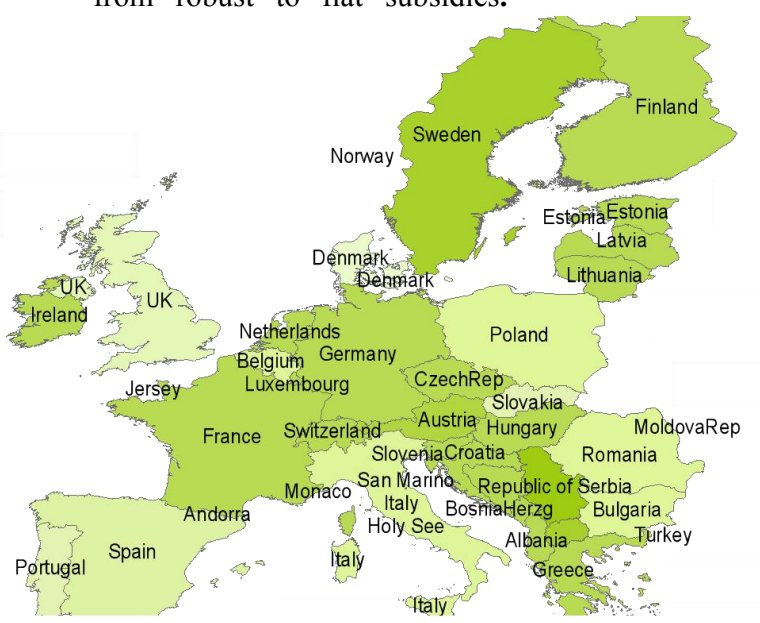

Figure 5b; Water demand, percentage change, from "flat" to "robust" subsidies.

Figures 5a and $\mathbf{5 b}$ show the distribution of water demand by EU countries. Figure 5a in percentage terms compares the difference between water demand under "historic" versus "robust" subsidies, and Figure 5b - "flat" versus "robust" subsidies. In Figure 5a, Baltic and northern countries under "robust" subsidies are characterized by higher water demand than under "flat" and "historic", which in figures is indicated by darker green colors. Central countries (e.g., Hungary, Czech Republic, etc.), "robust" subsidies increase the water demand, if compared both with "historic" and "flat"; in Germany, "robust" subsidies lead to the decrease and in France - to slight increase of the demand compared with "historic" scheme, Figure 5a. In the southern region (e.g. Spain, Italy) "robust" water demand is lower than in other schemes, which also corresponds to lower irrigated area expansion, Figure 4.

\subsection{Pillar II measures}

Storage is one of structural measures which can enable to achieve long-term sustainable rural development goals of 
Pillar II. As we show with numerical results, it address almost all "priorities for the new rural 1 development policy for 2014-2020" (Eropean Commission, 2017a). We explicitly investigate only the effects of implementing robust grain storage, which also allows us to analyze the synergies and trade-offs between other measures and variables. For example, grain reserves introduce flexibility into supply-demand-trade relations. They also allow grain prices to be controlled. Storage introduction decreases the demand for other structural measures, such as irrigation infrastructure. Storage of specific grains allows harvested products to be transferred from good to bad years to ensure food-feed-biofuel-water security. This way storage can reduce the demand for arable land otherwise required to hedge possible production shocks. Storage facilities can be viewed as insurance reserves when no other sources of supply, domestic or foreign, are available, for instance, in the case of correlated production shocks or restricted trade or trade bans.In this paper we discuss robust demand for grain storage and the ways to estimate it at regional and at EU levels. Further analysis needs to consider possible trade offs, crowding out effects of public storage (or subsidies for private storage) on privately organised storage, and ways for a robust public-private partnership in grain storage,which is a topic for future research.The data on investments, maintenance, and operational costs of different grain storage techniques have been compiled from the literature (e.g. Gustafson 1958; Deaton and Laroque 1992 and references therein).

\subsubsection{Robust grain storage}

In stochastic GLOBIOM, the demand for grain storage is estimated as a production shortfall in locations where current production does not meet demand (no self-sufficiency) and where trade is either not possible or too expensive. In the example of two regions (section 3), the robust scenario-dependent shortfalls are calculated as a solutions of equation (4) and can be explicitly defined as $y^{*}\left(x^{*}, \omega^{s}\right)=\max \left\{0, d-a_{1}\left(\omega^{s}\right) x_{1}-a_{2}\left(\omega^{s}\right) x_{2}\right\}$, where $\omega^{s}$ denotes scenarios of potential yield shock, $s=1,2, \ldots$. In the general stochastic GLOBIOM, the shortfalls are calculated for 28 EU countries as a solution of multidimentional probabilistic equations specifying probabilities (or a percentage of shock scenarios) when the targeted level of food-feed-biofuels production and environmental constraints is "allowed" to be unfulfilled, i.e. acceptable level of systemic insolvency (Ermolieva et al., 2016).

Stochastic GLOBIOM maximizes profits and minimizes costs including costs for grain storage. High demand for wheat, corn, rice, soya both in domestic and international markets, raises prices and require more agricultural land to be allocated to these crops. In other words, acreage under wheat, corn, rice, soya production can be viewed as a function of domestic crop prices, export and import prices, production costs, risk-expossure, feasible technologies, and security constraints. If stochastic GLOBIOM calculates some grain reserve, this means that the net profits from this crop are minimal and the crop can be substituted by more profitable and demanded crops. For example, stochastic GLOBIOM calculates that reserves of about 240 and 3376 thousand tons of rape and sunflower, respectively, are the least costly options to reach food-feed self-sufficiency and fulfill environment targets at the EU level. The result can be also interpreted as a recommendation to decrease biodiesel targets by roughly the equivalent of the calculated oil crops reserve, which would allow to fulfill security and resource constraints at lower prices. Figure 6 depicts distribution of robust rape and sunflower storage corresponding to robust allocation of subsidies.
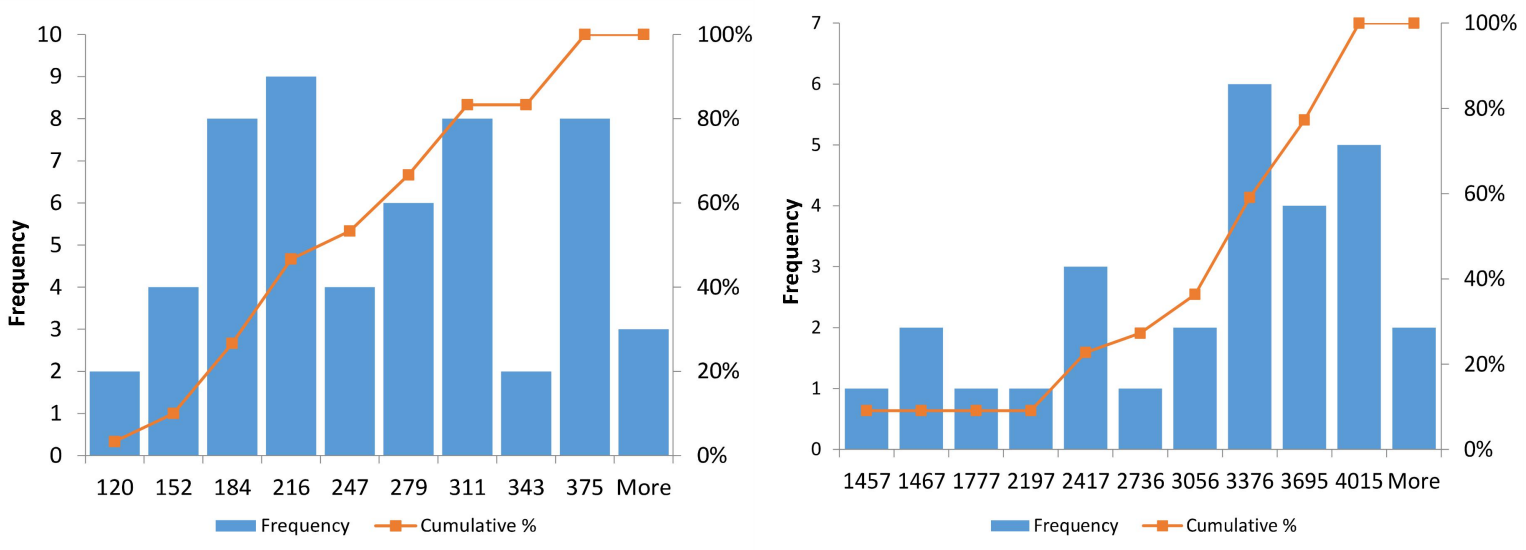

a. Rape
b. Sunflower

Figure 6; Distribution of robust production shortages (or demand for storage capacity) in each of the stochastic yield shock scenarios, in thousand tons, at EU level. Frequency refers to the absolute number of shortages within a range identified on the horizontal axis. Cumulative refers to the percentage of total shortages at or below the value on the horizontal axis.

\subsubsection{Irrigation system expansion}

As grain storage hedges production risks, it allows savings on investment inirrigation systems.According to stochastic GLOBIOM, EU grain reserves of about 240 and 3376 thousand tons of rape and sunflower can avoid investment in irrigation of about 200thousand hectares of agricultural land and decrease water consumption by about $16 \%$ at the EU level. By varying the parameters reflecting costs of storage and/or water infrastructure, trade-offs can be investigated between the demand and feasibility of domestic grain savings, irrigation land expansion,and interregional trade; that is, the model analyzes if precautionary grain stocks are cheaper than hedging production risks through increased irrigation, and/or expost imports.

In locations where water supply does not meet demand, the demand for irrigation infrastructure and water storage capacities (reservoirs) can be estimated in a similar way to (and in combination with) the demand forgrain storage facilities. The water shorffalls determine the demand for water-saving technologies, storage, etc., able to stabilize production and farmers' welfare at the required level.

\section{Discussion and conclusion}

This paper argues that, in the face of risks and uncertainties, the assessment and implementation of new CAP measures can be improved by using the stochastic integrated assessment model GLOBIOM. The stochastic model derives strategies that are optimal and robust with respect to various possible scenarios rather than only one scenario, which happens when traditional deterministic assessment models are used. The latter evaluate impacts, costs, and benefits, and thus the effectiveness of measures in a scenario-by-scenario manner, which may lead to maladaptation and the need to reverse decisions if an other-than-expected scenario occurs. Stochastic GLOBIOM allows for simultaneous minimization of costs associated with two types of decision: long-term strategic, implemented before the real state of nature is observed, and short-term operational, after additional information about uncertainties is "learned."

Currently, allocation of CAP funds to countries and pillars may not be the most efficient way of supporting farmers to adapt to climate change. For example, the flat-rate system can shift payments from less risk-exposed to more risk-exposed countries (and vice versa), which can affect the production of vital commodities like wheat, corn, rice, soya, sunflower, and rape. Robust paiments, on the contrary, can substantially increase, if compared with the effects of flat payments, the self-sufficiency and adaptive capacity of regions toward climatic risks and uncertainties. Introduction of grain storages further facilitates climatic risk hedging. The demand for storage capacity was evaluated based on the distribution of production shortfalls in locations, regional self-sufficiency policies, FFWE security considerations, and storage maintenance (including running) costs (exogenous variable) vs import costs (endogenous variable calculated by GLOBIOM). It was shown that rather moderate storage facilities would decrease water demand by agriculture; for example,under a scenario of robust subsidies combined with storage, the irrigated area can be decreased by $20 \%$ over time. The benefits of grain storage depend on the interplay between various variables, for example, prices, trade flows, shocks, etc., and are therefore determined endogenously by the model. Analysis of the demand for storage in the EU allows the feasibility of (high) biofuel targets under production risks and inelastic demand for wheat, corn, rape, sunflower, namely, biofuel sources, to be investigated.

\section{References}

1. Balkhausen O, Banse M, Grethe H. Modelling CAP decoupling in the EU: A comparison of selected simulation models and results. Journal of Agricultural Economics 2008; 59(1): 57-71.

2. Deaton A., Laroque G. Competitive storage and commodity price dynamics. Journal of Political Economy 1996; 104 (5): 896-923.

3. ECONADAPT (2016). ECONADAPT Toolbox: Stochastic modelling for robust decision-making: The Common 
Agricultural Policy. The Economics of Climate Change Adaptation (ECONADAPT, 603906, EU FP7) Project

Report. (http://econadapt.eu,

http://econadapt-toolbox.eu/stochastic-modelling-robust-decision-making-common-agricultural-policy).

4. Ermoliev Y, Hordijk L. Global changes: Facets of robust decisions. In: Marti K, Ermoliev Y, Makowski M, Pflug G (eds), Coping with uncertainty: Modeling and policy issue. Berlin: Springer Verlag 2003.

5. Ermoliev Y, von Winterfeldt D. Systemic risk and security management. In Ermoliev Y, Makowski M, Marti K (eds), Managing safety of heterogeneous systems: Lecture notes in economics and mathematical systems. Berlin, Heidelberg: Springer Verlag 2012; 19-49.

6. Ermolieva T, Havlík P, Ermoliev Y, et al. Integrated management of land use systems under systemic risks and security targets: A stochastic global biosphere management model. Journal of Agricultural Economics 2016a; 67(3): 584-601.

7. Ermolieva T, Biewald A, Boere E, et al. (2016b). Overview report on major uncertainties related to climate impacts and socio-economic costs, and policy recommendations related to the effectiveness of adaptation options. The Economics of Climate Change Adaptation (ECONADAPT, 603906, EU FP7)

Deliverable 7.3.(http://econadapt.eu/resources).

8. European Commission. Adapting to climate change: Towards a European framework for action. White Paper. 1.4.2009 COM (2009) 147 final. Brussels: European Commission.

9. European Commission. Impact assessment guidelines. Brussels: European Commission 2009b. (http://ec.europa.eu/smart- regulation/impact/commission_guidelines/docs/iag_2009_en).

10. European Commission. CAP towards 2020 impact assessment: Direct payments.Brussels: European Commission 2011. (http://ec.europa.eu/agriculture/policy-perspectives/ impact-assessment/cap-towards-2020/report/annex3a-d_en.pdf).

11. European Commission. Overview of CAP reform 2014-2020. Agricultural policy perspectives brief. No. 5, December 2013. Brussels: European Commission.

(http://ec.europa.eu/agriculture/policy-perspectives/policy-briefs/05_en.pdf).

12. European Commission. Regulation No. 1307/2013 of the European Parliament and of the Council establishing rules for direct payments to farmers under support schemes within the framework of the common agricultural policy and amending Annex X to that regulation. C(2014) 1476 final. Brussels: European Commission. (http://ec.europa.eu/transparency/regdoc/rep/3/2014/EN/3-2014-1476-EN-F1-1.Pdf).

13. European Commission. The Water Framework Directive and the Floods Directive: Actions towards the 'good status' of EU water and to reduce flood risks 2015.

(http://ec.europa.eu/environment/water/water-framework/pdf/4th_report/COM_2015_120_en.pdf).

14. European Commission (2017). CAP explained: Direct payments for farmers $2015-2020$. (https:/ec.europa.eu/agriculture/sites/agriculture/files/direct-support/direct-payments/docs/direct-payments-schem es_en.pdf).

15. European Commission (2017a). Fact Sheets on the European Union - 2017. (http://www.europarl.europa.eu/RegData/etudes/fiches_techniques/2013/050206/04A_FT(2013)050206_EN.pdf).

16. European Commission Rural Development 2014-2020. (https://ec.europa.eu/agriculture/rural-development-2014-2020_en).

17. European Parlament (2010). The single payment scheme after 2013 : New approach - new targets. (http://www.europarl.europa.eu/studies).

18. FAO (2016).http://faostat3.fao.org/browse/Q/QC/E.

19. Gohin A. Assessing the CAP reform: Sensitivity of modelling decoupled policies. Journal of Agricultural Economics 2006; 57: 415-440.

20. Havlík P, Schneider U, Schmid E, et al. Global land-use implications of first and second generation biofuel targets. Energy Policy 2011; 39: 5690-5702.

21. Heal G, Kriström B. Uncertainty and climate change. Environmental and Resource Economics 2002; $22: 3-39$.

22. Helming J, Peerlings J. Economic and environmental effects of a flat rate for Dutch agriculture. NJAS 2014; 68: 53-60.

23. IAEA. The Role of probabilistic safety assessment and probabilistic safety criteria in nuclear power plant safety. Vienna: International Atomic Energy Agency (IAEA) 1992. (http://books.google.at/books?id=J-ZSAAAAMAAJ).

24. IEEP(2000). The environmental impacts of irrigation in the European Union. A report to Environmental Directorate of the European Commissions. Inst for European Environmental Policy, London, in association with the Polytechnic University of Madrid and the University of Athens. London: IEEP. (http://ec.europa.eu/ environment/agriculture/pdf/irrigation.pdf).

25. JRC (2015). An EU-wide individual farm model for Common Agricultural Policy Analysis (IFM-CAP). (http://publications.jrc.ec.europa.eu/repository/bitstream/JRC92574/jrcreport_jrc92574.pdf).

26. Koundouri P., Laukkanen M., Myyrä S., Nauges C. The effects of EU agricultural policy changes on farmers' risk attitudes. European Review of Agricultural Economics 2009; 36(1): 53-7. 
27. Mosnier C, Ridier A, Képhaliacos C, et al. Economic and environmental impact of the CAP mid-term review on arable crop farming in South-western France. Ecological Economics 2009; 68: 1408-1416.

28. Nelson GC, Valin H, Sands R, et al. Climate change effects on agriculture: Economic responses to biophysical shocks. PNAS 2013; 111: 3274-3279.

29. WHO (1985). Energy and protein requirements. World Health Organization (WHO)Technical Report Series No. 724, Report of a joint FAO/WHO/UNU expert consultation. Geneva: WHO. 